\title{
Ephedorae herba Decreases Lipopolysaccharide-Induced Cyclooxgenase-2 Protein Expression and NF- $\kappa$ B-Dependent Transcription in C6 Rat Glioma Cells
}

\author{
Kohichi Aoki ${ }^{1}$, Tohru Yamakuni ${ }^{1}$, Masaaki Yoshida ${ }^{2}$, and Yasushi Ohizumi ${ }^{1}{ }^{1 *}$ \\ ${ }^{I}$ Department of Pharmaceutical Molecular Biology, Graduate School of Pharmaceutical Sciences, Tohoku University, \\ Aoba, Aramaki, Aoba-ku, Sendai 980-8578, Japan \\ ${ }^{2}$ Research Laboratory, Kotaro Pharmaceutical Co., Ltd., 43-3, Suga-cho,Takatsuki, Osaka 569-0022, Japan
}

Received April 27, 2005; Accepted May 26, 2005

\begin{abstract}
We studied the effects of Mao (Ephedrae herba) on lipopolysaccharide (LPS)induced expression of inducible cyclooxygenase (COX-2) in C6 rat glioma cells. Western blot analysis showed that Mao inhibited LPS-induced expression of COX-2 protein, but not that of constitutive cyclooxygenase. Reporter gene assays showed that Mao reduced LPS-inducible NF- $\kappa \mathrm{B}-$ dependent transcription that plays a crucial role in induction of COX-2 gene expression. This crude drug decreased LPS-induced $\mathrm{I} \kappa \mathrm{B} \alpha$ degradation in a concentration-dependent manner without affecting LPS-induced $\mathrm{I} \kappa \mathrm{B}$ phosphorylation. These results suggest that Mao prevents LPS-induced NF- $\kappa$ B-dependent transcription by inhibiting $\mathrm{I} \kappa \mathrm{B}$ degradation and suppresses an increase in COX-2 protein expression in C6 cells.
\end{abstract}

Keywords: Ephedrae herba, COX-2 gene expression, NF- $\kappa$ B-dependent transcription

Prostaglandins (PGs), arachidonic acid (AA) metabolites of the cyclooxygenase (COX) pathway, are major mediators in the regulation of inflammation and immune function (1). The interplay between $\mathrm{PGE}_{2}$ and other local factors, including inflammatory cytokines, is likely to influence the outcome of inflammatory and immune responses in the central nervous system (CNS). It has been therefore suggested that clinical control of AA metabolism, particularly $\mathrm{PGE}_{2}$ production, appears beneficial to patients with inflammatory conditions (2).

COX is the rate-limiting enzyme in PG production. This enzyme exists as two isoforms, namely constitutive COX (COX-1) and inducible COX (COX-2). These isoforms originate from two distinct genes, but are structurally conserved $(1,3)$. COX-1 serves as a constitutive enzyme responsible for PG synthesis that is essential for fluid and electrolyte homeostasis, gastric acid secretion, and platelet aggregation, while COX-2 is induced by inflammatory stimuli, and growth factors and glucocorticoids (4).

Activation of nuclear factor- $\kappa \mathrm{B}(\mathrm{NF}-\kappa \mathrm{B})$ has been

*Corresponding author. FAX: +81-22-795-6850

E-mail: ohizumi@mail.pharm.tohoku.ac.jp recently reported to actually participate in the transcriptional activation of COX-2 gene induced by interleukin-1 (5), tumor necrosis factor- $\alpha$ (6), and lipopolysaccharide (LPS) (7). Furthermore the LPS-induced activation of the COX-2 gene has been shown to be mediated by inhibitor $\kappa \mathrm{B}$ (I $\kappa \mathrm{B})$ kinase (IKK), which specifically catalyzes $\mathrm{I} \kappa \mathrm{B}$ phosphorylation followed by its degradation and the subsequent NF- $\kappa \mathrm{B}$ nuclear translocation, leading to a stimulation of the cis-acting $\kappa \mathrm{B}$ element-mediated transcription (8).

Mao (Ephedrae harba) has been used for many years as one component of various traditional Chinese medicines effective for the treatment of multiple symptoms of cold and allergy (9). Consistently, in the earlier study, we have revealed that this crude drug inhibits IgEmediated histamine release from rat basophilic leukemia (RBL-2H3) cells (10). Here we provide the first evidence that $\mathrm{Mao}$ decreases expression of COX-2 protein and NF- $\kappa \mathrm{B}$-dependent transcription in $\mathrm{C} 6$ glioma cells which is well known to be a useful model system for studying PG production in the astrocytes.

Ephedra herb employed in the present study was imported from China. Mao was prepared as the hotwater extract from Ephedra herb as described previously 
(10) and kindly supplied from Kotaro Pharmaceutical Co., Ltd. (Osaka). The yield of Mao extract from the plant was $17.2 \%$, and the total content of ephedrines, including $l$-ephedrine and $d$-pseudoephedrine (the ratio of the former to the latter was 2:1), of the extract was approximately $4 \%$. Fetal bovine serum, horse serum, and Ham's F-10 medium were purchased from Cell Laboratory (Cleveland, OH, USA), Dainippon Pharmaceutical Co., Ltd. (Osaka), and Invitrogen (Carlsbad, CA, USA), respectively. Anti-COX-1and anti-COX-2 antibodies, anti-14-3-3 $\beta$ antibody, anti-I $\kappa \mathrm{B} \alpha$ and anti$\mathrm{I} \kappa \mathrm{B} \beta$ antibodies, and anti-phospho-I $\kappa \mathrm{B} \alpha$ antibody were obtained from Cayman (Ann Arbor, MI, USA), Santa Cruz Biotechnology (Santa Cruz, CA, USA), and Cell Signaling Technology (Beverly, MA, USA), respectively. EndoFree Plasmid Maxi Kit, and phRG-TK vector and Dual-Luciferase ${ }^{\circledR}$ Reporter Assay System were purchased from QIAGEN K.K. (Tokyo) and Promega (Madison, WI, USA), respectively.

C6 cells were grown in F-10 medium containing 15\% horse serum, $2.5 \%$ fetal bovine serum in a $37^{\circ} \mathrm{C}$ humidified incubator in an atmosphere of $5 \% \mathrm{CO}_{2}-$ $95 \%$ air (11). Under this culture condition, the $\mathrm{pH}$ of the culture medium was approximately 7.4.

For immunoblotting, C6 cells were seeded onto 35$\mathrm{mm}$ dishes at the density of $2.0 \times 10^{5}$ cells per dish. Two days after seeding, cells were treated with or without Mao for $3 \mathrm{~h}$. Thereafter cells were incubated with or without $1 \mu \mathrm{g} / \mathrm{mg}$ LPS for an additional $6 \mathrm{~h}$. Western blot analyses were conducted as described previously (11): Cells were lysed by addition of SDSPAGE sample buffer. The protein samples were subjected to SDS-PAGE and then transferred electrically onto polyvinylindene difluoride membranes (Immobilon P; Millipore Corporation, Bedford, MA, USA). The blots were incubated with 5\% skim milk in Tris-buffered saline containing $0.05 \%$ Tween 20 at $25^{\circ} \mathrm{C}$ for $1 \mathrm{~h}$ and incubated with anti-COX-1, anti-COX-2-, anti-I $\kappa \mathrm{B} \alpha$, anti- $\mathrm{I} \kappa \mathrm{B} \beta$, anti-phospho- $\mathrm{I} \kappa \mathrm{B} \alpha$, or anti-14-3-3 $\beta$-antibodies at $4{ }^{\circ} \mathrm{C}$ overnight. The blots were washed several times and incubated with a 1:2000 dilution of horseradish peroxidase-conjugated affinity-purified secondary antibodies in Tris-buffered saline/Tween 20 containing 5\% skim milk at $25^{\circ} \mathrm{C}$ for $1 \mathrm{~h}$. Immunoreactive signals were visualized by incubation of the blots with chemiluminescence assay reagents, followed by exposing them to Hyperfilm ECL (Amersham Biosciences, ).

For the transcription activity assay, C6 cells were plated onto 48 -well plates at the density of $1.2 \times 10^{4}$ cells per well. After culture for $48 \mathrm{~h}$, cells were transfected with $0.19 \mu \mathrm{g}$ of firefly luciferase reporter plasmids of $\mathrm{pNF}-\kappa \mathrm{B}_{5}$-Luc firefly luciferase reporter construct containing five repeated NF- $\kappa$ B-responsive elements. Cells were co-transfected with $0.01 \mu \mathrm{g}$ of phRG-TK plasmid to normalize transfection efficiency as described previously (11). Thirteen hours later, cells were preincubated in the presence or absence of Mao for $3 \mathrm{~h}$ and incubated with or without $1 \mu \mathrm{g} / \mathrm{ml}$ LPS for $8 \mathrm{~h}$. Cells were harvested to determine each luciferase activity using the Dual-Luciferase ${ }^{\circledR}$ Reporter gene assay System (Promega).

The data are expressed as the means \pm S.E.M., and a significant difference $(P<0.05)$ was analyzed by analysis of variance (ANOVA).

COX is a key enzyme for prostaglandin production because this enzyme is involved in the rate-limiting step in the conversion of AA to prostaglandins (12). We examined whether $M a o$ affected the expressions of COX-1 and COX-2 proteins in C6 cells treated with LPS by Western blot analysis. In untreated cells, expressions of COX-1 and COX-2 proteins were detected. When treated with LPS, C6 cells showed an increase in expressions of COX-2 but not COX-1 proteins (Fig. 1). Mao was observed to inhibit the LPS-induced increase in expression of COX-2 protein in a concentrationdependent manner, although Mao exhibited no effects on expressions of COX-1 protein (Fig. 1). Also Mao had little effect on the cell viability at the concentrations ranging from 50 to $400 \mu \mathrm{g} / \mathrm{ml}$ (data not shown).

Activation of NF- $\kappa$ B participates in the induction of expression of COX-2 mRNA by LPS (13). Therefore, to examine whether Mao actually inhibits NF- $\kappa \mathrm{B}$-dependent transcription activity in LPS-induced C6 cells, we next conducted transient transfection of $\mathrm{C} 6$ cells with pNF $\kappa$ B-Luc, an NF- $\kappa$ B-dependent luciferase reporter plasmid, and assayed the luciferase activity in C6 cells treated with vehicle or Mao in the absence or presence of LPS. This crude drug was found to inhibit the LPSinduced NF- $\kappa \mathrm{B}$-dependent transcription and exhibited a concentration dependent inhibition. On the other hand, Mao has no effect on the basal NF- $\kappa$ B-dependent transcription (Fig. 2). We further analyzed effects of

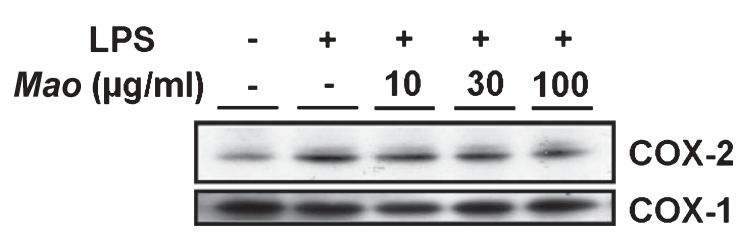

Fig. 1. Concentration-dependent inhibitory effects of Mao on the LPS-induced expression of COX protein in C6 rat glioma cells. Cells were plated at a density of $2 \times 10^{5}$ cells/dish and cultured for $48 \mathrm{~h}$. After pretreatment with Mao at the indicated concentrations for $3 \mathrm{~h}$, cells were treated with $1 \mu \mathrm{g} / \mathrm{ml}$ LPS for $6 \mathrm{~h}$ and then harvested to analyze the expression of COX proteins. Western blot analysis was performed using anti-COX-1 and anti-COX-2-antibodies. Similar results were obtained from at least two independent experiments. 


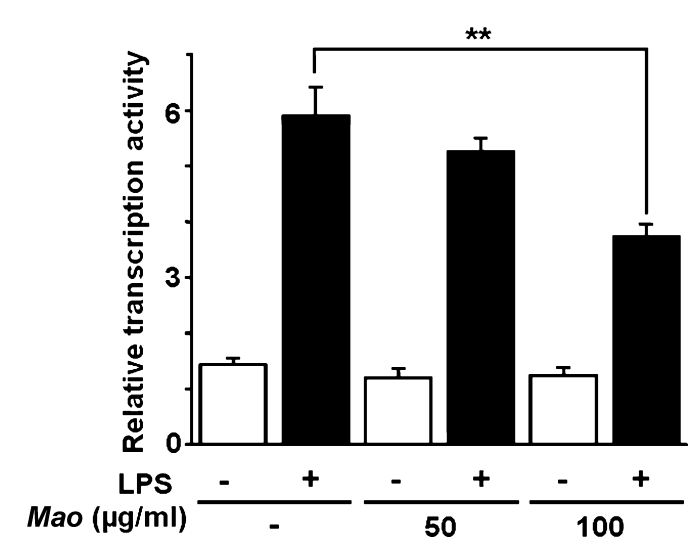

Fig. 2. Effects of Mao on LPS-induced NF- $\kappa \mathrm{B}$-dependent transcription in C6 rat glioma cells. After 48-h culture, cells were transfected with $0.19 \mu \mathrm{g}$ of pNF- $\kappa \mathrm{B}-$ Luc reporter plasmid and $0.01 \mu \mathrm{g}$ of phRG-TK plasmid. Cells were pretreated with or without Mao at the indicated concentrations for $3 \mathrm{~h}$ and were treated with or without $1 \mu \mathrm{g} / \mathrm{ml}$ LPS for $8 \mathrm{~h}$. Cells were harvested to determine luciferase activity. Luciferase activity was determined as described under the experimental procedures and the relative transcription activity was calculated as the ratio of firefly luciferase activity to the Renilla luciferase one. Each column represents the mean \pm S.E.M. of relative $\mathrm{NF}-\kappa \mathrm{B}-$-mediated transcription activity $(\mathrm{n}=4) .{ }^{* *} P<0.01$, compared with the value upon treatment with LPS in the absence of Mao.

Mao on the phosphorylation and degradation of $\mathrm{I} \kappa \mathrm{B} \alpha$ in C6 cells treated with LPS by Western blotting, since the LPS-inducible phosphorylation of $\mathrm{I} \kappa \mathrm{B}$ led to its degradation which results in the activation of NF- $\kappa \mathrm{B}-$ dependent transcription $(8,11)$. In $\mathrm{C} 6$ cells, both $\mathrm{I} \kappa \mathrm{B} \alpha$ and $\mathrm{I} \kappa \mathrm{B} \beta$ proteins were expressed and appeared to be degraded following treatment with LPS. It was shown that $M a o$ inhibited LPS-induced degradation of $\mathrm{I} \kappa \mathrm{B} \alpha$ but not that of $\mathrm{I} \kappa \mathrm{B} \beta$ in a concentration-dependent manner with no effects on LPS-induced phosphorylation of $\mathrm{I} \kappa \mathrm{B} \alpha$ (Fig. 3: A and B).

Mao has been widely used as a component of various traditional Chinese medicines in East Asia, China, and Japan for many years, and we reported that it can exert an anti-allergic action (10). In the present study, it was for the first time found that Mao suppressed LPSinduced increase in COX-2 protein expression without affecting the cell viability in $\mathrm{C} 6$ rat glioma cells. We also demonstrated that this crude drug inhibited the LPS-induced stimulation of NF- $\kappa$ B-dependent transcription by preventing LPS-induced degradation of $\mathrm{I} \kappa \mathrm{B} \alpha$ without any effects on LPS-induced phosphorylation of $\mathrm{I} \kappa \mathrm{B} \alpha$ in $\mathrm{C} 6$ cells. These findings suggested that Mao inhibits LPS-induced augmentation of COX-2 gene expression accompanied by prevention of an $\mathrm{I} \kappa \mathrm{B} / \mathrm{NF}-$ $\kappa \mathrm{B}$-dependent intracellular signaling pathway.

COX-2 gene expression is induced as an immediateearly gene in certain types of cells in response to a wide

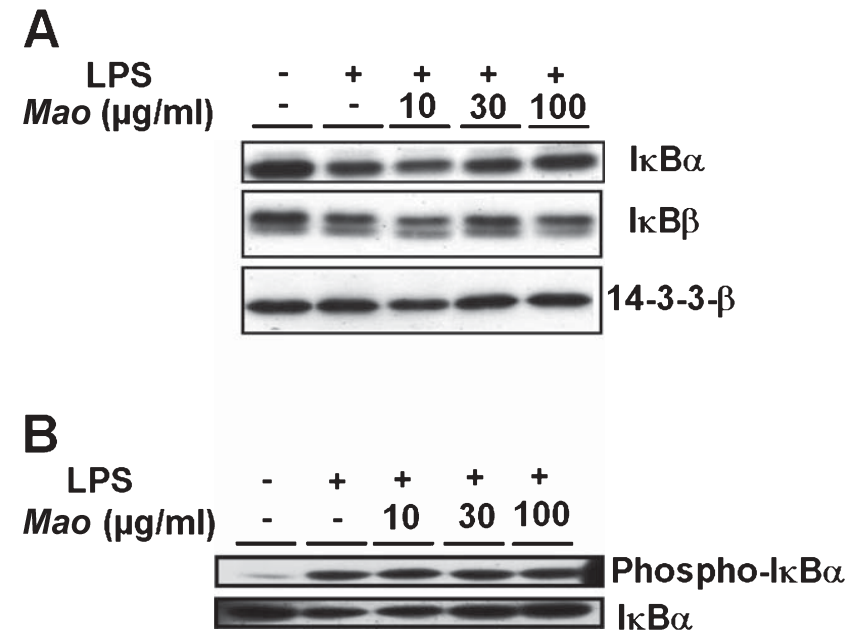

Fig. 3. Effects of Mao on the LPS-induced degradation and phosphorylation of $\mathrm{I} \kappa \mathrm{B}$ in $\mathrm{C} 6$ rat glioma cells. Cells were plated at a density of $2 \times 10^{5}$ cells $/$ dish and cultured for $48 \mathrm{~h}$. After pretreatment with Mao at the indicated concentrations for $3 \mathrm{~h}$, cells were treated with $1 \mu \mathrm{g} / \mathrm{ml}$ LPS for $30 \mathrm{~min}$ and harvested to analyze the degradation of $\mathrm{I} \kappa \mathrm{B} \alpha$ and $\mathrm{I} \kappa \mathrm{B} \beta$ proteins. Blots were probed with anti- $\mathrm{I} \kappa \mathrm{B} \alpha$ or anti-I $\kappa \mathrm{B} \beta$-antibody and then reprobed with anti-14-3-3- $\beta$ antibody to verify that each lane contained equal amount of proteins. Similar results were obtained from at least two independent experiments.

variety of inflammatory stimuli $(4,12)$. It has been demonstrated that LPS induces COX-2 gene expression via NF- $\kappa$ B-mediated transcription in U937 cells (7) and C6 cells (11). Furthermore, we found that LPS induced increase in the protein expression of COX-2 but not COX-1 in C6 cells as described previously (11) and that Mao inhibited the LPS-induced increase in expression of COX-2 protein in a concentration-dependent manner. In addition, $l$-ephedrine, a major component of $M a o$, exhibited no effects on the LPS-induced increase in expression of COX-2 protein in C6 cells (unpublished observations), raising the possibility that $l$-ephedrine may not be responsible for inhibition of LPS-induced augmentation of expression of COX-2 protein by Mao. It was also shown that this crude drug did tend to reduce the LPS-induced augmentation of the luciferase activity in C6 cells transfected with phPES2 $(-327 /+59)$-Luc, a human $\mathrm{COX}-2$ reporter gene containing the NF- $\kappa \mathrm{B}-$ responsive element (11), at $200 \mu \mathrm{g} / \mathrm{ml}$ (unpublished observations). The most important finding of the present study is that Mao has the pharmacological activity to prevent stimulation of NF- $\kappa \mathrm{B}$, a central mediator of inflammation by LPS, by inhibiting LPS-induced degradation of $\mathrm{I} \kappa \mathrm{B}$, although the inhibitory mechanism of LPS-induced degradation of $\mathrm{I} \kappa \mathrm{B}$ remains to be defined. It is therefore possible that Mao inhibits an $\mathrm{I} \kappa \mathrm{B} / \mathrm{NF}-\kappa \mathrm{B}-$ dependent signaling probably by prevention of a ubiquitination step of $\mathrm{I} \kappa \mathrm{B} \alpha$ or a protein degradation step after 
the ubiquitination to decrease the LPS-induced augmentation of COX-2 gene expression in vivo.

In conclusion, we found that Mao suppressed LPSinduced expression of COX-2 protein and activation of an $\mathrm{I} \kappa \mathrm{B} / \mathrm{NF}-\kappa \mathrm{B}$-dependent signaling pathway in $\mathrm{C} 6$ cells. These findings suggest the possible anti-inflammatory action of Mao in vivo.

\section{Acknowledgments}

This work was partly supported by a Grant-in-Aid for Scientific Research from the Ministry of Education, Culture, Sports, Science, and Technology of Japan. We thank Dr. H. Inoue, National Cardiovascular Center Research Institute, for helpful discussions and Dr. J. Fujisawa, Kansai Medical University, for providing the $\mathrm{NF}-\kappa \mathrm{B}$ promoter construct.

\section{References}

1 Smith WL, Dewitt DL, Garavito RM. Cyclooxygenase: structural, cellular, and molecular biology. Annu Rev Biochem. 2000;69:145-182.

2 Goldstein IM. Agents that interfere with arachidonic acid metabolism. In: Gallin JI, Snyderman R, editors. Inflammation, basic, principles and clinical correlates. 2nd ed. New York: Raven Press; 1992. p. 1127-1137.

3 Dixon DA, Kaplan CD, McIntyre TM, Zimmerman GA, Prescott SM. Post-transcriptional control of cyclooxygenase-2 gene expression. J Biol Chem. 2000;275:11750-11757.

4 Dewitt DL, Meade EA. Serum and glucocorticoid regulation of gene transcription and expression of prostaglandin $\mathrm{H}$ synthase-1 and prostaglandin $\mathrm{H}$ synthase-2 isozyms. Arch Biochem Biophys. 1993;306:94-102.

5 Newton R, Kuitert LM, Bergmann M, Adcock IM, Barnes PJ.
Evidence for involvement of NF-kappaB in the transcriptional control of COX-2 gene expression by IL-1beta. Biochem Biophys Res Commun. 1997;237:28-32.

6 Yamamoto K, Arakawa T, Ueda N, Yamamoto S. Transcriptional roles of nuclear factor $\kappa \mathrm{B}$ and nuclear factor-interleukin-6 in the tumor necrosis factor a-dependent induction of cyclooxygenase-2 in MC3T3-E1 cells. J Biol Chem. 1995;270: 31315-31320.

7 Griseavage JM, Wilk S, Ignarro LJ. Inhibitors of the proteasome pathway interfere with induction of nitric oxide synthase in macrophages by blocking activation of transcription factor NF-kappa B. Proc Natl Acad Sci USA. 1996;93:3308-3312.

8 Inoue $\mathrm{H}$, Tanabe $\mathrm{T}$. Transcriptional role of the nuclear factor kappa B site in the induction by lipopolysaccharide and suppression by dexamethasone of cyclooxygenase-2 in U937 cells. Biochem Biophys Res Commun. 1998;244:143-148.

9 Ohashi Y, Nakai Y, Furuya H, Ezaki Y, Hachikawa K, Tamura T, et al. Clinical effect of Mao-Bushi-Saishin-To in patients with obstinate nasal blockage due to perennial rhinitis. Pract Otol. (Kyoto) 1992;85:1845-1853. (text in Japanese with English abstract)

10 Saito S, Maruyama Y, Kamiyama S, Nakahata N, Ohizumi Y. Ephrdrae herba in Mao-Bushi-Saishin-To inhibits IgE-mediated histamine releases and increase cAMP content in RBL-2H3 cells. J Pharmacol Sci. 2004;95:41-46.

11 Nakatani K, Yamakuni T, Kondo N, Arakawa T, Oosawa K, Shimura S, et al. $\gamma$-Mangostin inhibits inhibitor- $\kappa \mathrm{B}$ kinase activity and decreases lipopolysaccharide-induced cyclooxygenase2 gene expression in C6 rat glioma cells. Mol Pharmacol. 2004;66:667-674.

12 Rosen GD, Birkenmeier TM, Raz A, Holtzman MJ. Identification of a cyclooxygenase-related gene and its potential role in prostaglandin formation. Biochem Biophys Res Commun. 1989;164:1358-1365.

13 D'Acquisto F, Iuvone T, Rombola L, Sautebin L, Rosa MD, Carnuccio R. Involvement of NF- $\kappa \mathrm{B}$ in the regulation of cyclooxygenase-2 protein expression in LPS-stimulated J774 macrophages. FEBS Lett. 1997;418:175-178. 